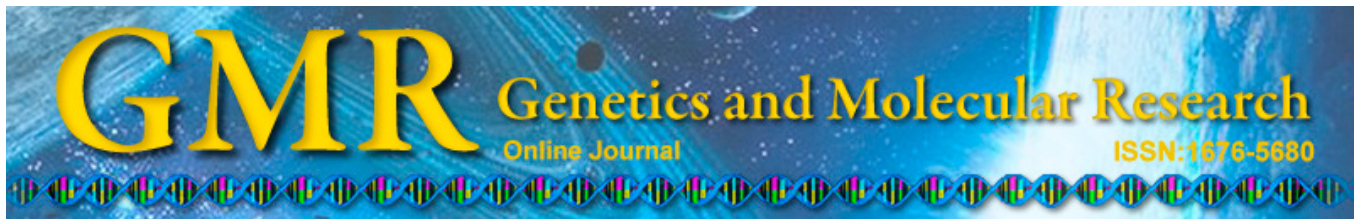

\title{
Marker-assisted selection in breeding silkworm strains with high tolerance to fluoride, scaleless wings, and high silk production
}

\author{
M.W. Li ${ }^{1,2}$, H.J. Yu ${ }^{1}$, X.L. Yi ${ }^{1}$, J. Li ${ }^{1}$, F.Y. Dai ${ }^{3}$ and C.X. Hou ${ }^{1,2}$ \\ ${ }^{1}$ Sericultural Research Institute, \\ Jiangsu University of Science and Technology, Zhenjiang, China \\ ${ }^{2}$ Sericultural Research Institute, \\ Chinese Academy of Agricultural Sciences, Zhenjiang, China \\ ${ }^{3}$ State Key Laboratory of Silkworm Genome Biology, \\ Southwest University, Chongqing, China \\ Corresponding author: C.X. Hou \\ E-mail: cxhou587@163.com
}

Genet. Mol. Res. 14 (3): 11162-11170 (2015)

Received December 19, 2014

Accepted May 18, 2015

Published September 22, 2015

DOI http://dx.doi.org/10.4238/2015.September.22.10

\begin{abstract}
In the silkworm (Bombyx mori), tolerance to fluoride and scaleless wings are controlled by the dominant gene $\operatorname{Dtf}$ (dominant tolerance to fluoride) and recessive gene $n l w$ (no Lepidoptera wings), respectively, and these genes have been mapped by using simple sequence repeat and sequence tag site markers. Marker-assisted evaluation and selection of silkworms with fluoride tolerance and scaleless wings were used for predicting fluoride resistance and scaleless wings in backcrossed animals. A silkworm strain was bred using this method, and its economic characteristics were found to be similar to those of commercial silkworms. These methods will therefore be useful for silkworm breeding programs and in screening for two or more characteristics of interest for segregating populations.
\end{abstract}

Key words: Bombyx mori; Tolerance to fluoride; Scaleless wings; Marker-assisted selection 


\section{INTRODUCTION}

Silkworms are one of the most economically important insects because of the important role of the silk industry in many developing countries. However, along with economic development, varying degrees of pollution appear in industrial areas. Fluoride is one of the materials in the environment in varying amounts, and it can accumulate in some agricultural products. High concentrations of fluoride are harmful to both humans and animals and cause toxicity such as endemic fluorosis ( $\mathrm{Li}$ and Cao, 1994) and industrial fluorosis (Czerwinski et al., 1988; Dote et al., 2000). Fluoride is also harmful to silkworms, and silk production has been seriously affected by fluoride pollution in China (Lin et al., 2006).

There is a layer of scales on the surface of the wings of silkworm moths, which is a typical characteristic for lepidopteran adults. Multicolored scales are important in butterfly mimicry, and they are also an important innovation during lepidopteran evolution (Galant et al., 1998). Diverse butterfly wing patterns are primarily the result of the deposition of colored pigments formed during wing scale maturation (Koch et al., 2000a,b). Although the colored wings are beautiful, the scales are not good for human health if there are high amounts of them floating in the air, particularly indoors. In silkworm egg production farms, when the moths hatch, there are numerous airborne scales, and they are harmful to the workers.

Although silkworm strains with high tolerance to fluoride or scaleless wings can be bred by conventional breeding techniques, long periods are needed for selecting the desired characteristics, particularly when these are recessive. Fortunately, two mutants, $n l w$ (scaleless wings) and $D t f$ (dominant tolerance to fluoride), have been discovered in silkworms (Zhang and Qin, 1991; Lin et al., 1996, 1997). The allele $n l w$ is recessive, and although there are few scales on the wing its vitality is as good as that of the wild type (Zhang and Qin, 1991). This mutant has been mapped using simple sequence repeat (SSR) and sequence tag site (STS) markers (Wang et al., 2010). Dtf controls tolerance to fluoride. The larvae can survive even when they are fed with mulberry leaves treated with $200 \mathrm{mg} / \mathrm{kg}$ of NaF solution, but the larvae of highly susceptible silkworm strains will die even at a concentration as low as $50 \mathrm{mg} / \mathrm{kg}$. This gene has also been mapped by using SSR markers (Bai et al., 2008).

DNA molecular markers, including restriction fragment length polymorphisms (Botstein et al., 1980), random amplified polymorphic DNA (Williams et al., 1990), amplified fragment length polymorphisms (Vos et al., 1995), and SSRs (Tautz, 1989) have been used in studying genetic diversity, strain identification, and genetic linkage, and to assist in marker selection in many species. These markers have been studied for use in genetic diversity analysis (Nagaraju et al., 2001; Li et al., 2005; Zhu et al., 2014; Pereira et al., 2013; Tokuda et al., 2014), mapping mutants and positional cloning (Meng et al., 2009; Wang et al., 2013; Falcão et al., 2014), and mapping quantitative trait loci (Lu et al., 2004; Zhan et al., 2009; Li et al., 2013).

Because of the development of molecular biological techniques, marker-assisted selection (MAS) has been widely used in crop and animal breeding (Steele et al., 2006; Yau, 2005; Hou et al., 2013; Kuang et al., 2014). Hou et al. (2013) reported MAS of silkworm strains not susceptible to desonucleosis virus by using SSR markers. This method is highly efficient and can be used to select more than one characteristic during breeding procedures. Here, we report the use of the MAS methods in selecting silkworm strains with $D t f$ and $n l w$ characteristics. 


\section{MATERIAL AND METHODS}

\section{Silkworm strains}

The T6 silkworm strain (Dtf/DtfDtf ) has high tolerance to fluoride; its larvae can survive with very few effects even when they are fed with mulberry leaves treated with $200 \mathrm{mg} /$ $\mathrm{kg}$ of NaF solution. There are few scales on the wings of the U13 silkworm strain $(n l w / n l w)$ but its vitality is as good as that of the wild type. The Jingsong strain $\left(++^{D t f} /+^{D t} ;+^{n l w} /+^{n l w}\right)$, which is susceptible to fluoride (all of the larvae will die when they are fed mulberry leaves treated with $50 \mathrm{mg} / \mathrm{kg}$ of $\mathrm{NaF}$ solution) and has wild-type wings, is a productive commercial strain widely used in Chinese sericulture. These strains are maintained at the Sericulture Research Institute, Chinese Academy of Agriculture Sciences.

\section{DNA extraction and PCR}

DNA samples were extracted from one-quarter of the body of whole moths, from the whole body of young larvae (1st-4th instar), except the midgut, and from silk glands of unhealthy large larvae (5th instar). The moth/larva bodies (or silk glands) were ground with a mechanical homogenizer in a microcentrifuge tube and suspended in a DNA extraction buffer (50 mM Tris-HCl, pH 8.0, $100 \mathrm{mM} \mathrm{NaCl}, 20 \mathrm{mM}$ EDTA) containing $150 \mathrm{~g} / \mathrm{mL}$ proteinase $\mathrm{K}$. After digestion with proteinase $\mathrm{K}\left(50^{\circ} \mathrm{C}\right.$ for $\left.6-8 \mathrm{~h}\right)$, a phenol-chloroform extraction was performed, and the DNA was precipitated out with isopropanol. Purified DNA was dissolved in $0.1 \mathrm{X}$ TE buffer ( $\mathrm{pH} 8.0$ ). The DNA concentration was measured by spectrophotometry (BioPhotometer, Eppendorf, USA), and the samples were diluted to a concentration of $10 \mathrm{ng} /$ $\mu \mathrm{L}$ for use in polymerase chain reaction (PCR) analysis.

The PCRs were performed using an ABI 2720 Cycler (Lifetech, USA). The following PCR conditions were used for the microsatellite loci: 1) $95^{\circ} \mathrm{C}$ for $3 \mathrm{~min}, 63^{\circ} \mathrm{C}$ for $30 \mathrm{~s}$, and $72^{\circ} \mathrm{C}$ for $45 \mathrm{~s}$, followed by 14 cycles of $94^{\circ} \mathrm{C}$ for $45 \mathrm{~s}$, then a 14-step touchdown, decreasing by $0.5^{\circ} \mathrm{C}$ at each step to $56^{\circ} \mathrm{C}(40 \mathrm{~s})$, and $72^{\circ} \mathrm{C}$ for $1 \mathrm{~min}$, and 3$)$ a final elongation step of $10 \mathrm{~min}$ at $72^{\circ} \mathrm{C}$. PCR was performed in a final volume of $15 \mu \mathrm{L}$ containing $10 \mathrm{mM}$ Tris- $\mathrm{HCl}, \mathrm{pH} 8.4$, $50 \mathrm{mM} \mathrm{KCl}, 1.5 \mathrm{mM} \mathrm{MgCl}, 0.2 \mathrm{mM}$ of each dNTP, $0.2 \mu \mathrm{M}$ of each primer, $20 \mathrm{ng}$ genomic DNA, 0.5 U Taq polymerase (Takara, China), and distilled deionized water. For STS markers, PCR conditions were as follows: 1) $95^{\circ} \mathrm{C}$ for $\left.3 \mathrm{~min}, 2\right) 35$ cycles at $94^{\circ} \mathrm{C}$ for $40 \mathrm{~s}, 56^{\circ} \mathrm{C}$ for 40 $\mathrm{s}$, and $72^{\circ} \mathrm{C}$ for $1.5 \mathrm{~min}$, and 3) a final elongation step of $10 \mathrm{~min}$ at $72^{\circ} \mathrm{C}$. The PCR products from SSR markers were diluted to about $0.5 \mathrm{ng}(0.01 \mathrm{pM})$ per sample and were analyzed using an ABI377 DNA sequencer (ABI PRISM, Applied Biosystems, USA) or by $2 \%$ agarose gel if the differences of the DNA bands in different parents were sufficiently large to observe. The PCR products of STS markers were tested on $2 \%$ agarose gel.

\section{Strategy for MAS}

MAS was used to breed a new silkworm strain with scaleless wings and tolerance to fluoride, based on co-dominant SSR/STS markers linked to $n l w$ and $D t f$. For the cross-over experiments, a female of the Jingsong strain was crossed with a male of the T6 strain, and then (Jingsong x T6) females were mated to the U13 strain. Jingsong females were then crossed to 
(Jingsong x T6) x U13 to obtain $\mathrm{BC}_{1}$ and other backcross (BC) generations (six in total) males in order to evaluate their economic characteristics. In each generation, SSR and STS markers, located on either side of Dtf, S1214 and S121201, (Bai et al., 2008) and $n l w$, S1305 and cash2p, (Wang et al., 2010) were used to detect the genotype of male moths after they mated with Jingsong females. When backcrossing generations, only the heterozygous individuals from Jingsong and T6 in S1214 and S121201 and Jingsong and U13 in S1305 and cash2p were used. Otherwise, Jingsong-type homozygous animals were discarded. Self-mating within a generation was carried out in the $\mathrm{BC}_{6}$ generation, and these offspring were fed with $200 \mathrm{mg} / \mathrm{kg}$ NaF-polluted mulberry leaves. Scaleless-wing moths with good economic characteristics were selected from the surviving individuals and were self-mated to generate the next generation $\left(\mathrm{BC}_{6} \mathrm{~F}_{3}\right)$, and molecular markers were used to select the individuals that were homozygous at both the $D t f$ and $n l w$ sites. Thus, a new silkworm strain with good economic characteristics, high tolerance to fluoride, and scaleless wings was developed.

\section{RESULTS}

\section{Genotype of the markers in the MAS populations}

In each backcrossed generation, larvae with good health were selected, and the cocoon weight, cocoon shell weight, and other factors were evaluated, and then 24 male moths with highest economic characteristics were selected for backcrossing to Jingsong parents. After crossing, their genotypes were determined with respect to the four co-dominant markers (Table 1). According to each marker, the ratio of heterozygous and homozygous individuals was approximately 1:1. Approximately four to seven moths were heterozygous for these four markers in each generation (Table 2), and their offspring were selected as the next generation. In the $\mathrm{BC}_{6}$ generation, the individuals producing high-quality silk were selected to be selfcrossed, and 4 of 24 pairs were found to be heterozygous. After feeding with $\mathrm{NaF}$ pollutedmulberry leaves, the ratio of heterozygous and homozygous (T6 type) for S121201 and S1214 was nearly 2:1, but in scaleless-wing individuals, the cash2p and S1305 both showed nearly total homozygosity as in U13 because only scaleless-wing adults were selected to generate the $\mathrm{BC}_{6} \mathrm{~F}_{3}$ generation. When the T6 type homozygous for S121201 and S1214 were selected for breeding the next generation, $\mathrm{BC}_{6} \mathrm{~F}_{3}$, their offspring were all homozygous, as were the donor parents (T6 and U13). Figure 1 shows the model of the genotypes at the F11214 and cash2p locus of 12 male parents for $\mathrm{BC}_{2}$; only the offspring of the three heterozygous individuals were selected for the next generation. Figure 2 shows the genotype of 12 individuals at the F11214 locus of $\mathrm{BC}_{6} \mathrm{~F}_{2}$ individuals surviving after being fed with NaF-polluted-mulberry leaves; only the offspring of both parents that were homozygous as the $\mathrm{T} 6$ type were selected for the $\mathrm{BC}_{6} \mathrm{~F}_{3}$ generation. The ratio of the T6 type to the heterozygous type was consistently found to be 1:2.

\section{Fluoride tolerance and scaleless wings in the populations selected}

A total of 12 pairs from the $\mathrm{BC}_{6}$ generation, which demonstrated good economic characteristics, were mated to produce the $\mathrm{BC}_{6} \mathrm{~F}_{2}$ generation. All of the $\mathrm{BC}_{6} \mathrm{~F}_{2}$ individuals were fed with $200 \mathrm{mg} / \mathrm{kg} \mathrm{NaF}$-polluted mulberry leaves, and approximately three fourths of the individuals survived. In the surviving individuals, about one fourth had scaleless wings. The 
moths with scaleless wings and beneficial economic characteristics were selected to breed the $\mathrm{BC}_{6} \mathrm{~F}_{3}$ generation. The parents of the $\mathrm{BC}_{6} \mathrm{~F}_{3}$ generation $\left(\mathrm{BC}_{6} \mathrm{~F}_{2}\right.$ adults) were detected using S1214 and S121201 markers. Only the batch with both parents having the same homozygosity as $\mathrm{T} 6$ was preserved. The $\mathrm{BC}_{6} \mathrm{~F}_{3}$ population was again fed with NaF-polluted mulberry leaves. All of the individuals survived and had scaleless wings.

Table 1. Co-dominant markers used in the marker-assisted selection.

\begin{tabular}{lll}
\hline Marker symbol & F Primer sequence $\left(5^{\prime}-3^{\prime}\right)$ & R Primer sequence $\left(5^{\prime}-3^{\prime}\right)$ \\
\hline S121201 & AGTTCTTGCTTGTTTCCGTTCT & CGCCGTATGTATTTATTCCTCA \\
S1214 & AATGGATGCGTGCCAGTTTG & CGTTAGTTGCTCTACGCTTTTGG \\
cash2p & GTATAACAACTTTGGATTAATTGG & GATTGGACTCAGTATATTCG \\
S1305 & GCCTTTATTAACGGATGCGGG & AATGAGCGATTTAGTGGGCAA \\
\hline
\end{tabular}

Table 2. Genotype of backcrossing individuals at the two SSR loci.

\begin{tabular}{|c|c|c|c|c|c|c|c|c|c|}
\hline \multirow{2}{*}{$\begin{array}{l}\text { Backcrossing } \\
\text { generation }\end{array}$} & \multicolumn{2}{|c|}{ S121201 } & \multicolumn{2}{|c|}{$\mathrm{S} 1214$} & \multicolumn{2}{|c|}{ cash $2 p$} & \multicolumn{2}{|c|}{$\mathrm{S} 1305$} & \multirow{2}{*}{$\begin{array}{c}\text { Number of } \\
\text { heterozygotes } \\
\text { at } 4 \text { loci }\end{array}$} \\
\hline & $\begin{array}{c}\text { Number of } \\
\text { heterozygotes }\end{array}$ & $\begin{array}{c}\text { Number of } \\
\text { homozygotes }\end{array}$ & $\begin{array}{c}\text { Number of } \\
\text { heterozygotes }\end{array}$ & $\begin{array}{c}\text { Number of } \\
\text { homozygotes }\end{array}$ & $\begin{array}{c}\text { Number of } \\
\text { heterozygotes }\end{array}$ & $\begin{array}{c}\text { Number of } \\
\text { homozygotes }\end{array}$ & $\begin{array}{c}\text { Number of } \\
\text { heterozygotes }\end{array}$ & $\begin{array}{c}\text { Number of } \\
\text { homozygotes }\end{array}$ & \\
\hline (Jingsong x T6) x U13 & 6 & 0 & 6 & 0 & 12 & 0 & 12 & 0 & \\
\hline $\mathrm{BC}_{1}$ & 12 & 12 (Js Type) & 12 & 12 (Js Type) & 13 & 11 (Js Type) & 12 & 12 (Js Type) & 6 \\
\hline $\mathrm{BC}_{2}$ & 12 & 12 (Js Type) & 12 & 12 (Js Type) & 12 & 12 (Js Type) & 12 & 12 (Js Type) & 7 \\
\hline $\mathrm{BC}_{3}^{2}$ & 9 & 12 (Js Type) & 15 & 13 (Js Type) & 11 & 12 (Js Type) & 13 & 12 (Js Type) & 4 \\
\hline $\mathrm{BC}_{4}$ & 13 & 12 (Js Type) & 11 & 12 (Js Type) & 10 & 12 (Js Type) & 14 & 12 (Js Type) & 5 \\
\hline $\mathrm{BC}_{5}^{4}$ & 14 & 6 (Js Type) & 10 & 7 (Js Type) & 12 & 12 (Js Type) & 12 & 12 (Js Type) & 5 \\
\hline \multirow[t]{2}{*}{$\mathrm{BC}_{6}$} & $q 11$ & 13 (Js Type) & $\$ 12$ & 12 (Js Type) & $\$ 12$ & 12 (Js Type) & +12 & 12 (Js Type) & 6 \\
\hline & 12 & 12 (Js Type) & 12 & 12 (Js Type) & 12 & 12 (Js Type) & 11 & 13 (Js Type) & $\begin{array}{r}85 \\
833\end{array}$ \\
\hline $\mathrm{BC}_{6} \mathrm{~F}_{2}$ & 16 & 8 (T6 Type) & 17 & 7 (T6 Type) & 0 & 24 (U13 Type) & 1 & 23 (U13 Type) & 0 \\
\hline $\mathrm{BC}^{6} \mathrm{~F}_{3}$ & 0 & 24 (T6 Type) & 0 & 24 (T6 Type) & 0 & 24 (U13 Type) & 0 & 24 (U13 Type) & 0 \\
\hline
\end{tabular}

Js = Jingsong.

\section{$\begin{array}{lllllllllllllll}\mathbf{A}_{1} & 2 & 3 & 4 & 5 & 6 & 7 & 8 & 9 & 10 & 11 & 12 & 13 & 14 & 15\end{array}$}

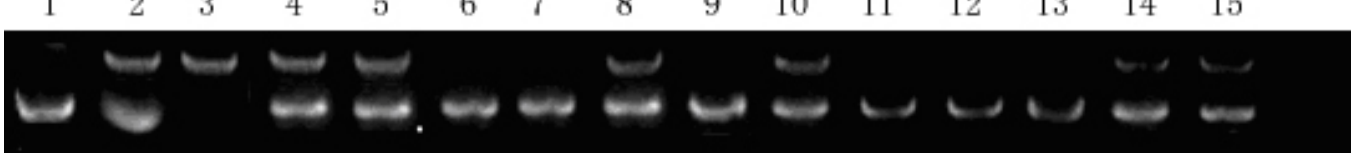

\section{B}

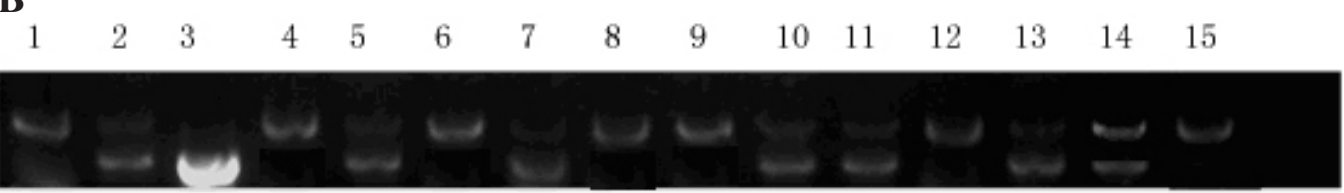

Figure 1. Model of the genotypes at the F11214 and cash2p locus of 12 male parents for $\mathrm{BC}_{2}$. A. F11224, B. cash2p. A. Lane 1 = Jingsong; lane 2 = (Jingsong $\mathrm{x} \mathrm{T} 6) \mathrm{F}_{1}$; lane $3=\mathrm{T} 6$; lanes $4-15=\mathrm{BC}_{1}$ males for generating the $\mathrm{BC}_{2}$ generation. B. Lane $1=$ Jingsong; lane $2=($ Jingsong $\mathrm{x} U 13) \mathrm{F}_{1}$; lane $3=\mathrm{U} 13$; lanes $4-15 \mathrm{BC}_{1}$ males for generating the $\mathrm{BC}_{2}$ generation. Nos. 5, 10, and 14 in these 12 individuals were heterozygous for both markers, and they are candidates for the parents of the next generation. 


\begin{tabular}{|c|c|c|c|c|c|c|c|c|c|c|c|c|c|c|}
\hline 1 & 2 & 3 & 4 & 5 & 6 & 7 & 8 & 9 & 10 & 11 & 12 & 13 & 14 & 15 \\
\hline$C$ & & & 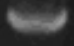 & & 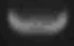 & & & $\theta$ & & & & 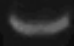 & & \\
\hline & $x$ & 80 & & $\log$ & & $k 0)$ & 6 & & 5 & $x^{2}$ & 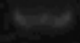 & & 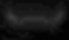 & $5=$ \\
\hline
\end{tabular}

Figure 2. Genotype at the F11214 locus of 12 surviving $\mathrm{BC}_{6} \mathrm{~F}_{2}$ individuals after being fed with NaF-polluted mulberry leaves. Lane $1=\mathrm{T} 6$; lane 2 = (Jingsong x T6) $\mathrm{F}_{1}$; lane $3=$ Jingsong; lanes 4-15= $\mathrm{BC}_{6} \mathrm{~F}_{2}$ individuals for generating the $\mathrm{BC}_{6} \mathrm{~F}_{3}$ generation. Nos. 4, 6, 9, and 13 were homozygous for the T6 type, and only both parents of $\mathrm{BC}_{6} \mathrm{~F}_{3}$ showing this genotype would be selected.

\section{Economic characteristics of each generation}

Using the T6 strain as the donor parent of $D t f$ and $\mathrm{U} 13$ as the donor parent of scaleless wings, the Jingsong strain was used as a recurrent parent to improve the new silkworm strain's economic characteristics, and co-dominant SSR/STS markers were used to ensure that the Dtf and $n l w$ genes would not be lost during backcrossing. As shown in Table 3, during backcrossing the economic characteristics of the new strain were improved quickly and were similar to those of the parent Jingsong strain, and its larva-pupa survival rate was higher than that of the recurrent parent, Jingsong (Table 3).

\begin{tabular}{|c|c|c|c|c|c|c|c|c|}
\hline Strain/Generation & Year & $\begin{array}{c}\text { Duration of 5th } \\
\text { instar larvae (D:H) }\end{array}$ & $\begin{array}{c}\text { Duration of feeding } \\
\text { period (D:H) }\end{array}$ & $\begin{array}{c}\text { Cocoon } \\
\text { weight }(\mathrm{g})\end{array}$ & $\begin{array}{l}\text { Cocoon shell } \\
\text { weight }(\mathrm{g})\end{array}$ & $\begin{array}{l}\text { Ratio of cocoon } \\
\text { shell (\%) }\end{array}$ & $\begin{array}{c}\text { Ratio of cocoon } \\
\text { mortality }(\%)\end{array}$ & $\begin{array}{c}\text { Larva-pupa } \\
\text { survival rate }(\%)\end{array}$ \\
\hline (Jingsong $\mathrm{x}$ T6) $\mathrm{F}_{1}$ & $2009 \mathrm{Sp}$ & 7:00 & $22: 12$ & 1.583 & 0.337 & 21.29 & 1.69 & 95.33 \\
\hline (Jingsong $\mathrm{x}$ T6) x U13 & 2009Au & $6: 18$ & $22: 00$ & 1.229 & 0.206 & 16.76 & 2.68 & 91.78 \\
\hline $\mathrm{BC}_{1}$ & $2010 \mathrm{Sp}$ & $7: 12$ & $23: 12$ & 1.596 & 0.359 & 22.49 & 2.33 & 94 \\
\hline $\mathrm{BC}_{2}$ & 2010Au & 7:00 & $23: 06$ & 1.683 & 0.386 & 22.94 & 3.67 & 93.62 \\
\hline $\mathrm{BC}_{3}^{2}$ & $2011 \mathrm{Sp}$ & $7: 18$ & $24: 00$ & 1.873 & 0.441 & 23.55 & 2.18 & 96.54 \\
\hline $\mathrm{BC}_{4}$ & 2011Au & $7: 12$ & $23: 12$ & 1.692 & 0.397 & 23.46 & 4.67 & 91.23 \\
\hline $\mathrm{BC}_{5}^{4}$ & 2012Sp & $8: 00$ & $24: 12$ & 1.851 & 0.461 & 24.91 & 2.42 & 95.81 \\
\hline $\mathrm{BC}_{6}$ & 2012Au & $7: 18$ & $24: 00$ & 1.803 & 0.439 & 24.35 & 6.55 & 83.65 \\
\hline $\mathrm{BC}_{6} \mathrm{~F}_{2}$ & $2013 \mathrm{Sp}$ & $8: 06$ & $24: 18$ & 1.975 & 0.493 & 24.96 & 3.75 & 91.72 \\
\hline $\mathrm{BC}_{6} \mathrm{~F}_{3}^{2}$ & 2013Au & $8: 12$ & $24: 12$ & 1.928 & 0.463 & 24.01 & 5.67 & 89.33 \\
\hline Jingsong & 2013Au & $7: 18$ & $24: 18$ & 1.871 & 0.462 & 24.69 & 7.39 & 86.67 \\
\hline $\mathrm{BC}_{6} \mathrm{~F}_{4}$ & 2014Sp & $8: 06$ & $25: 06$ & 1.963 & 0.489 & 24.91 & 2.35 & 94.68 \\
\hline Jingsong & $2014 \mathrm{Sp}$ & $8: 12$ & $25: 12$ & 2.032 & 0.510 & 25.10 & 3.23 & 92.69 \\
\hline U13 & 2014Sp & $5: 00$ & $18: 12$ & 0.835 & 0.127 & 15.21 & 2.67 & 95.02 \\
\hline T6 & $2014 \mathrm{Sp}$ & $6: 18$ & $22: 00$ & 1.528 & 0.365 & 23.89 & 2.07 & 95.33 \\
\hline
\end{tabular}

*Sp = spring; $\mathrm{Au}=$ autumn; $\mathrm{D}=$ day; $\mathrm{H}=$ hour.

\section{Homozygosity in male moths of each backcrossed generation}

Two SSR and STS markers that showed polymorphism between Jingsong and T6 or Jingsong and U13 were selected from each linkage group on the SSR (Zhan et al., 2009) and STS (Li et al., 2013) linkage maps to detect homozygosity of the backcrossed males throughout the breeding procedure. An average of 7 linkage groups were homozygous for Jingsong in the $\mathrm{BC}_{1}$ generation, and an average of 18 linkage groups were homozygous for Jingsong in the $\mathrm{BC}_{2}$ generation. In the $\mathrm{BC}_{3}$ and $\mathrm{BC}_{4}$ generations, the number of homozygous linkage 
groups increased to 22 and 25 , respectively. Only one marker in 24 individuals was found to be heterozygous in the $\mathrm{BC}_{6}$ generation, while the others were all homozygous, except those linked to $D t f$ and $n l w$ (data not shown).

\section{DISCUSSION}

During economic development, air pollution can become a serious problem in some regions. Fluoride is one of the main components in polluted air and is particularly noticeable in autumn. Fluoride is harmful not only to human beings but also to mulberry trees and silkworms. Although air pollution has improved in China, it is still serious in some regions. The $D t f$ allele controls tolerance to fluoride in silkworms. In our experiments, the Jingsong parent was sensitive to fluoride and its health affected when it was fed $50 \mathrm{mg} / \mathrm{kg} \mathrm{NaF-treated} \mathrm{mulberry} \mathrm{leaves,} \mathrm{and}$ nearly all of the individuals died if the larvae were fed with $100 \mathrm{mg} / \mathrm{kg} \mathrm{NaF}$-treated mulberry leaves. The best way to control reduced silk output is to breed silkworm varieties that have tolerance to fluoride. Wing scales are typical characteristics in lepidopteran insects, but they are harmful for the workers on the silkworm egg production farms. The $n l w$ allele controls the formation of scaleless wings in silkworms, and such a strain produces fewer scales during copulation and egg laying. Using this type of strain will be better for the workers' health.

It is possible to breed commercial silkworm strains that have tolerance to fluoride or scale wings, and such strains have been bred using crossing methods (Xu et al., 2006; Shen et al., 2011). To improve economic viability, the larvae of each generation should be fed with fluoride-treated mulberry leaves. It is complicated to make the Dtf gene homozygous (Xu et al., 2006). Although it is easy to make the $n l w$ allele homozygous, it is difficult to make sure that it would not be lost during backcrossing. The development time will be significantly extended if heterozygous strains are self-crossed (Shen et al., 2011). Of course it is very complicated to develop one silkworm strain with two or more concurrent characteristics. Normally, we would introduce one allele of interest to one strain, and after it was fixed, we would introduce the second allele. This method, however, would take a very long time to achieve the goal of one strain with the two desired alleles.

MAS using molecular biology techniques has been widely used in crop breeding and it has also been applied in silkworm breeding. In 2013, we reported breeding a new silkworm strain that was not susceptible to densonucleosis virus by using MAS methods in backcrossing generations (Hou et al., 2013). Breeding silkworm strains with two or more characteristics in one breeding plan would be more complicated. In this research, we attempted to breed a silkworm strain with concurrent tolerance to fluoride and with scaleless wings, and we succeeded in breeding this silkworm variety in 4 years by using MAS methods.

Although the $D t f$ allele could be screened by feeding each generation with fluoridepolluted mulberry leaves, it would be much more labor intensive. In addition, wet leaves are not good for the larvae although the surviving ones show tolerance to fluoride. By using MAS methods, we can focus only on the economic characteristics desired, and the desired allele can be selected by molecular markers later.

In conclusion, we used SSR/STS markers as tools to select two characteristics in one silkworm breeding plan. After successive crossing with two donor parents, a new silkworm strain was bred after six generations of backcrossing, and its economic characteristics were similar to those of its recurrent parent. These results prove that MAS methods are highly efficient in breeding silkworm varieties with two or more desired characteristics. 


\section{ACKNOWLEDGMENTS}

Research supported by the National Natural Science Foundation of China (grant \#31372375), the Natural Science Foundation of Jiangsu Province (\#BK20131240), and the Project of the State Key Laboratory of Silkworm Genome Biology (\#sklsgb2013020).

\section{REFERENCES}

Bai HC, Xu AY, Li MW, Zhao YP, et al. (2008). SSR based linkage and mapping analysis of dominant endurance to fluoride gene (def) in the silkworm Bombyx mori. ACTA Seric. Sin. 34: 191-196.

Botstein D, White RL, Skolnick M and Davis RW (1980). Construction of genetic linkage map in man using restriction length polymorphisms. Am. J. Hum. Genet. 32: 314-331.

Czerwinski E, Nowak J, Dabrowska D, Skolarczyk AB, et al. (1988). Bone and joint pathology in fluoride-exposed workers. Arch. Environ. Health 43: 340-43343.

Dote T, Kono K, Usuda K, Nishiura H, et al. (2000). Toxicokinetics of intravenous fluoride in rats with kidney damage caused by high-dose fluoride exposure. Int. Arch. Occup. Environ. Health 73: S90-92.

Falcão LHO, Furtado-Neto MAA, Maggioni R and Faria VV (2014). Prospective molecular markers for the identification of illegally traded angelsharks (Squatina) and dolphin (Sotalia guianensis). Genet. Mol. Res. 13: 9710-9717.

Galant R, Skeath, JB, Paddock S, Lewis DL, et al. (1998). Expression pattern of a butterfly achaete-scute homolog reveals the homology of butterfly wing scales and insect sensory bristles. Curr. Biol. 8: 807-813.

Hou C, Sun P, Guo X, Huang Y, et al. (2013). Marker-assisted selection in breeding silkworm strains with high silk production and resistance to the densonucleosis virus. Genet. Mol. Res. 12: 4171-4178.

Koch PB, Behnecke B and French-Constant RH (2000a). The molecular basis of melanism and mimicry in a swallowtail butterfly. Curr. Biol. 10: 591-594.

Koch PB, Lorenz U, Brakefield PM and French-Constant RH (2000b). Butterfly wing pattern mutants: developmental heterochrony and coordinately regulated phenotypes. Dev. Genes Evol. 210: 536-544.

Kuang M, Yang WH, Wang F, Xu HX, et al. (2014). Screening of highly informative and representative microsatellite markers for genotyping of major cultivated cotton varieties. Genet. Mol. Res. 13: 9777-9786.

Li B, Wang XY, Hou CX, Xu AY, et al. (2013). Genetic analysis of quantitative trait loci for cocoon and silk production quantity in Bombyx mori. Eur. J. Entomol. 110: 205-213.

Li JX and Cao SR (1994). Recent studies on endemic fluorosis in China. Fluoride 27: 125-128.

Li MW, Shen L, Xu AY, Miao XX, et al. (2005). Genetic diversity among the silkworm (Bombyx mori L., Lep., Bombycidae) germplasm revealed by microsatellites. Genome 48: 802-810.

Lin CQ, Yao Q and Wu DX (1996). Investigation and analysis on endurance fluoride of silkworm strain resources. Acta Seric. Sin. 22: 253-255.

Lin CQ, Mi YD, Yao Q, Wu DX, et al. (1997) The discovery of dominant endurance to fluoride gene in silkworm, Bombyx mori L. Acta Seric. Sin. 23: 237-239.

Lin CQ, Xu AY, Hou CX, Zhang YH, et al. (2006). Breeding of highly endurance fluoride silkworm strains Huayuan X Dongsheng for spring season and its characters. China Seric. 27: 30-32.

Lu C, Li B, Zhao A and Xiang Z (2004). QTL mapping of economically important traits in Silkworm (Bombyx mori). Sci. China C Life Sci. 47: 477-484.

Meng Y, Katsuma S, Mita K and Shimada T (2009). Abnormal red body coloration of the silkworm, Bombyx mori, is caused by a mutation in a novel kynureninase. Genes Cells 14: 129-140.

Nagaraju J, Reddy KD, Nagaraja GM and Sethuraman BN (2001). Comparison of multilocus RFLPs and PCR-based marker systems for genetic analysis of the silkworm, Bombyx mori. Heredity 86: 588-597

Pereira NC, Munhoz REF, Bignotto TS, Bespalhuk, et al. (2013). Biological and molecular characterization of silkworm strains from the Brazilian germplasm bank of Bombyx mori. Genet. Mol. Res. 12: 2138-2147.

Shen XJ, Zhao QL, Tang SM and Zhang ZF (2011). Studies on the breeding methods for scaleless silkworm strain. China Seric. 32: 15-16.

Steele KA, Price AH, Shashidhar HE and Witcombe JR (2006). Marker-assisted selection to introgress rice QTLs controlling root traits into an Indian upland rice variety. Theor. Appl. Genet. 112: 208-221.

Tautz D (1989). Hypervariability of simple sequences as a general source for polymorphic DNA markers. Nucleic Acids Res. 17: 6463-6471.

Tokuda M, Martins MM and Izar P (2014). Transferability of microsatellites for studies on the social behavior of the tufted 
capuchin monkey (genus Sapajus). Genet. Mol. Res. 13: 9910-9914.

Vos P, Hogers R, Bleeker M, Reijans M, et al. (1995). AFLP: a new technique for DNA fingerprinting. Nucleic Acids Res. 23: 4407-4414.

Wang LY, Kiuchi T, Fujii T, Daimon T, Li MW, et al. (2013). Mutation of a novel ABC transporter gene is responsible for the failure to incorporate uric acid in the epidermis of ok mutants of the silkworm, Bombyx mori. Insect Biochem. Mol. Biol. 43: 562-571.

Wang XY, Li MW, Zhao YP, Xu AY, et al. (2010). Mapping of non-lepis wing gene nlw in silkworm (Bombyx mori) using SSR and STS markers. Yi Chuan 32: 54-58.

Williams JGK, Hanafey MK, Rafalski JA and Tingey SV (1990). DNA polymorphisms amplified by arbitrary primers are useful as genetic markers. Nucleic Acids Res. 18: 6531-6535.

$\mathrm{Xu}$ AY, Lin CQ, Hou CX, Zhang YH, et al. (2006) Breeding of silkworm strain Huayuan X Dongshen endurance to fluoride and its characters. China Seric. 27: 30-32.

Yau YY, Santos K and Simon P (2005). Molecular tagging and selection for sugar type in carrot roots using co-dominant, PCR-based markers. Mol. Breed. 16: 1-10.

Zhan S, Huang J, Guo Q, Zhao Y, et al. (2009) An integrated genetic linkage map for silkworms with three parental combinations and its application to the mapping of single genes and QTL. BMC Genomics 10: 389-404.

Zhang Z F and Qin J (1991). Genetics study on the transparent wing silkworm moth (a primary report). Acta Seric. Sin. 17: 186-187.

Zhu SR, Li JL, Xie N, Zhu LM, et al. (2014) Genetic diversity based on SSR analysis of the cultured snakehead fish, Channa argus (Channidae), in China. Genet. Mol. Res. 13: 8046-8054. 